1 Universidade Federal de Pelotas (UFPel) - Pelotas (RS), Brasil.

kantorski@uol.com.br

2 Instituto Federal do Paraná (IFPR) - Palmas (PR), Brasil.

mhantonacci@gmail.com

3 Universidade Estadual do Centro Oeste (Unicentro) Irati (PR), Brasil.

psicopaulla@yahoo.com.br

4 Università degli Studi di

Torino (Unito) - Torino

(TO), Itália.

mariocardano@unito.it

5 Università degli Studi di

Perugia (UNIPG) - Perugia

(PG), Itália.

massimiliano.minelli@

unipg.it

\section{Grupos de ouvidores de vozes: estratégias e enfrentamentos}

\author{
Hearing voices groups: strategies and confrontations \\ Luciane Prado Kantorski1, Milena Hohmann Antonacci², Ana Paula Müller de Andrade ${ }^{\mathbf{3}}$, Mario \\ Cardano ${ }^{\mathbf{4}}$, Massimiliano Minelli5
}

RESUMO O objetivo deste artigo é discutir as estratégias utilizadas por diferentes grupos de pessoas que ouvem vozes, para o enfrentamento de tal experiência. Trata-se de um estudo etnográfico realizado junto a grupos italianos de ouvidores de vozes. Os dados, que foram obtidos no período entre outubro de 2014 e janeiro de 2016, através da observação participante, com registros em diários de campo, demonstram que estratégias de enfrentamento em espaço grupal, tais como o diálogo com as vozes, a busca de informação e a escrita sobre as mesmas são importantes para a superação das dificuldades decorrentes dessa vivência e estimulam o protagonismo daqueles que as ouvem.

PALAVRAS-CHAVE Saúde mental. Terapêuticas. Pacientes. Ouvidores de vozes.

ABSTRACT The objective of this article is to discuss the strategies used by different groups of people who hear voices, to cope with such experience. This is an ethnographic study carried out with italian groups of voice listeners. The data, that were obtained in the period between October 2014 and January 2016, through participant observation, with records in field diaries, demonstrate that coping strategies in group space, such as dialogue with the voices, the search for information and writing about them are important to overcome difficulties arising from this experience and stimulates the protagonism of those who hear them.

KEYWORDS Mental health. Therapeutics. Patients. Hearing voices. 


\section{Introdução}

As estratégias terapêuticas no campo da saúde mental têm sido ampliadas ao longo das últimas décadas, muitas delas voltadas para o protagonismo e o respeito às singularidades dos sujeitos que experimentam algum tipo de sofrimento mental. Tais estratégias ganham força em contextos socioculturais, históricos e políticos particulares e, em geral, estão alicerçadas na crítica aos saberes instituídos e no entendimento de que é possível a constituição de maneiras diferentes de enfrentamento e alívio dos sofrimentos dos sujeitos.

Nesse sentido, um fato relevante ocorreu enquanto Movimento Internacional de Ouvidores de Vozes, nascido na Holanda, na segunda metade dos anos 1980, seguido de um encontro fortuito e casual entre uma jovem senhora assediada por vozes, Patsy Hage, e um intrigante livro, 'Il crollo della mente bicamerale e l'origine della coscienza', publicado pelo psicólogo Julian Jaynes (2000). Antes deste encontro singular, Hage era assediada por vozes ameaçadoras, que os psicofármacos não conseguiam interromper. E o volumoso livro sustentava uma tese que a intrigava. Jaynes (2000) sustentava que a nossa mente era dividida em duas partes: uma parte objetiva, chamada deus; e uma parte subjetiva, chamada homem. Para o autor, era normal a mente arcaica ouvir, na própria cabeça, uma voz, aquela dos deuses, a convicção das coisas. Ele retomou ali os heróis da Grécia Antiga celebrados por Homero. À luz da tese da mente bicameral, Hage começou a perceber as vozes que a habitavam a partir de um novo registro, distante do estigma da patologia psiquiátrica. Ela se convenceu de gozar dos privilégios concedidos aos heróis da Grécia Antiga, de ouvir as vozes dos deuses (CARDANO; LEPORI, 2012; ROMME; ESCHER, 1997).

O psiquiatra que era responsável pelos cuidados de Hage, Marius Romme, a encorajou a compartilhar com outros pacientes sua própria descoberta, constituindo o primeiro núcleo de grupo de mútua ajuda da Rede de Ouvidores de Vozes, que estava para nascer. Esta prática, que autorizava o paciente psiquiátrico a interpretar a própria diferença, alheia a um registro patológico, se difunde primeiro na Holanda, depois no Reino Unido, dando vida à organização internacional Intervoice, propagada em todo o mundo (BARROS; SERPA JÚNIOR, 2014; CARDANO; LEPORI, 2012). Após ampla difusão, principalmente nos países de língua inglesa, o movimento de ouvidores de vozes ganhou projeção na Itália, no ano de 2011, com a constituição da associação Noi e Le Voci (CARDANO; LEPORI, 2012).

No Brasil, o movimento já conta com um blog - intervoicebrasil.blogspot.com.br - e com iniciativas em algumas cidades, como o Rio de Janeiro (BARROS; SERPA JÚNIOR, 2014).

Alguns dos pressupostos do movimento consistem em: os sujeitos detêm uma expertise sobre suas experiências; ouvir vozes é uma experiência singular, não necessariamente de sofrimento e patologizável (ainda que não se trate de negar a existência de uma doença); é possível criar estratégias para lidar com as vozes; é necessário desmedicalizar e romper com os estigmas advindos de uma leitura psiquiátrica dessas experiências; e é importante compartilhá-las em grupos de ajuda mútua. Estes pressupostos indicam a centralidade dos sujeitos e suas experiências singulares com as vozes, buscando, no compartilhamento destas com seus pares, estratégias para o enfrentamento das dificuldades que advêm de tal escuta.

Os grupos desenvolvidos não são homogêneos em termos de organização, funcionamento e regularidade, entre outros aspectos, a depender dos contextos socioculturais, bem como das circunstâncias que possibilitam seu surgimento. Em geral, os grupos progridem na perspectiva da ajuda mútua, compostos por ouvidores de vozes, que se reúnem sistematicamente para compartilhar tal experiência, compreendê-la e desenvolver estratégias de enfrentamento, de modo a recuperar o 
controle sobre suas próprias vidas (BAKER, 2012; COLEMAN; SMITH, 2006; ROMME; ESCHER, 1997).

Considerando a importância das experiências desenvolvidas pelo movimento de ouvidores de vozes para o campo da saúde mental, o objetivo deste artigo é discutir as estratégias propostas por grupos realizados no contexto italiano, para o enfrentamento da experiência de ouvir vozes, por seus participantes.

\section{Metodologia}

Este trabalho consiste em um estudo qualitativo, de abordagem etnográfica, realizado junto aos grupos de ouvidores de vozes, em três cidades do interior da Itália. Os grupos foram acompanhados por duas pesquisadoras, no período entre outubro de 2014 e janeiro de 2016. O percurso etnográfico iniciou-se em outubro de 2014, no acompanhamento ao grupo de Gubbio (Perúgia), e seguiu-se aí por seis meses. Já de março de 2015 a fevereiro de 2016, deu-se nos grupos Settimo Torinese (Turim) e San Giuseppe di Cairo (Savona), sendo utilizadas a observação participante e a descrição densa em diário de campo, além de entrevistas, como complementares. Nesses períodos, o percurso etnográfico incluiu a participação das pesquisadoras nas reuniões dos grupos e no acompanhamento de outras atividades na comunidade, e cuidadosamente as ingressou no campo, de modo a garantir-lhes o direito de entrada, a aceitação dos ouvidores de vozes e a formação do vínculo de confiança.

O trabalho de campo teve como ponto de partida o compartilhamento do local com eles, as normas que foram por eles estabelecidas, a linguagem constituída no próprio grupo social, suas crenças em relação às vozes, suas práticas e modos de lidar com elas, a atribuição de sentido às mesmas e as relações sociais entre os membros do grupo, desenvolvendo, em seguida, uma descrição minuciosa em diário de campo.

A escolha da abordagem etnográfica se deu por permitir uma compreensão ampliada das experiências dos sujeitos, sem encerrá-las em categorias prévias, e "levando a sério diferentes formas de pensamento e outras formas de conhecimento próprias a essas comunidades", como propõem Nunes e Torrenté (2013, P. 286).

Os grupos acompanhados reuniam-se com periodicidades diferentes, que variavam entre a semanal e a quinzenal, e duravam entre uma hora e meia e duas horas. Ocorriam dentro de serviços de saúde mental, coordenados por ouvidores de vozes e profissionais de saúde mental. Participava desses grupos um número variável entre 8 e 15 pessoas.

A inserção das pesquisadoras nos grupos se deu por meio de contato com os coordenadores, consulta prévia e concordância de todos os membros desses grupos. Os dados foram obtidos através da observação participante e os registros foram feitos em diários de campo.

Os dados estão identificados no texto conforme as iniciais das cidades onde os grupos foram acompanhados, aqui denominados: G, ST e SGC. Letras alfabéticas foram utilizadas para identificar os participantes dos grupos.

A pesquisa atendeu a todos os procedimentos éticos e foi aprovada pelo Comitê de Ética em Pesquisa da Faculdade de Medicina da Universidade Federal de Pelotas, por meio do parecer $\mathrm{n}^{\circ}$ 750.144, de 2014 .

\section{Discussão e resultados}

\section{Grupos de ouvidores de vozes: senti- dos e vínculos}

A organização de grupos de autoajuda/ajuda mútua compostos por ouvidores de vozes tem possibilitado a criação de espaços coletivos de compartilhamento dessas experiências. Tais grupos apostam na capacidade de produzir uma melhor convivência com as vozes, a partir do compartilhamento de vivências, informações e estratégias de enfrentamento. 
Um ponto que se destaca dentro dessa abordagem diz respeito à possibilidade de discutir as vozes como uma experiência real na vida dos sujeitos, sem a preocupação de classificá-las como expressão de um processo de adoecimento, ou religioso, mas sim em um contexto mais amplo de narrativas pessoais e de sentidos para aqueles que as experimentam.

Assim, os grupos têm o potencial de conferir legitimação a tais experiências, por meio do compartilhamento destas em um coletivo. $\mathrm{Ou}$ seja, representam um lugar seguro para falar sobre as vozes; um local para descobertas de significados para alcançar o controle sobre a experiência; um espaço de construção de redes sociais de suporte; um ambiente para desenvolver-se enquanto agente transformador na vida de outro membro do grupo (ZANNI, 2017).

Os ouvidores de vozes são pessoas fortemente estigmatizadas, portanto, tendem a valorizar a chance de conhecer outras pessoas com experiências semelhantes. Como consequência, os grupos de ouvidores de vozes têm se disseminado, fornecendo um contexto seguro para que seus participantes compartilhem experiências e permitam a divulgação de estratégias para lidar com as vozes, e ainda considerem crenças alternativas sobre elas (RUDDLE; MASON; WYKES, 2011).

Vale destacar que o fato de ouvir vozes que as demais pessoas não ouvem é relatado por muitos ouvidores como uma experiência perturbadora e até mesmo desesperadora. Romme e Escher (1997), ao caracterizarem a experiência de ouvir vozes, dividem-na em três fases: a fase de surpresa, a fase de organização e a fase de estabilização. A primeira fase, da surpresa, segundo os autores, é caracterizada pela maior parte dos que ouvem vozes como uma experiência de início vívido, súbito e surpreendente. No mesmo sentido, são os relatos dos participantes dos grupos acompanhados. Em algumas reuniões, tal fase pode ser reconhecida, como mostram os fragmentos a seguir:

G. diz que é muito difícil falar de como se sente.

Ela se sentiu muito assustada quando iniciaram as vozes, porque the diziam que era uma prostituta e ordenavam para que parecesse erotizada diante das pessoas. Era uma exposição muito grande da sua pessoa. Ela diz que não gosta de recordar tudo que fez. Era muito estranho, porque ela não se reconhecia no que estava fazendo. Sentia-se insegura, angustiada. (ST).

P. fala das vozes e do medo quando aquela muIher que ele ouvia Ihe dizia que era um pedófilo, pois pensava que todos ao seu redor acreditavam no que a voz dizia dele. Diz que foi um período muito difícil, porque não tinha confiança em ninguém. (ST).

O medo que caracteriza essa fase está ligado à construção social, que relaciona as vozes à loucura e à esquizofrenia, e ao pavor de ouvir vozes que outros não escutam. Essa experiência solitária, que está na ordem do tabu e é quase proibida de ser partilhada, faz com que o ouvidor de vozes reconheça a experiência como assustadora.

Outro aspecto importante é a relação do aparecimento das vozes, na maioria das vezes, com uma vivência de um trauma sofrido pelo ouvidor, parecendo ser mais grave quando as vozes iniciam na adolescênCia (BAKER, 2012; COLEMAN; SMITH, 2006; CONTINI, 2013A; ROMME; ESCHER, 1997). As experiências traumáticas são variadas e dizem respeito a singularidades e circunstâncias socioculturais e históricas, como, por exemplo, a relatada em uma das reuniões:

Logo no início da reunião, A. pergunta a $A b$. como ele está, pois ele demonstra claramente estar triste. [...] Ab. fala pouco, e tem muita dificuldade com a língua italiana. Conta que começou a ouvir as vozes logo que chegou à Itália. Relata que hoje está bem, porque as vozes Ihe disseram que o serviço é um lugar bom; e que as ouve somente quando chega ao abrigo. (ST).

No fragmento supracitado, o fato de ter passado por um processo muitas vezes traumático, como as imigrações que têm 
ocorrido na Europa, e, mais do que isto, estar na condição de imigrante (HATTON, 2016), são eventos marcantes na vida de Ab., que parece relacionar ambos os acontecimentos. Tais eventos podem desencadear o isolamento do sujeito e tornar a vivência do processo ainda mais solitária. Os grupos de ouvidores de vozes emergem como espaços de apoio e acolhimento às pessoas em seus sofrimentos.

Nesse sentido, as estratégias desenvolvidas nos grupos partem da ideia de que ouvir vozes não é o problema. O problema maior é a dificuldade do ouvidor em estabelecer algum tipo de relação com as suas vozes. Assim, tais estratégias se constituem como uma alternativa ao saber psiquiátrico tradicional, que caracteriza tais escutas como alucinações auditivas e verbais. Ao trabalhar em grupos, propõem incluir e valorizar as vivências subjetivas, e acompanhar seus desdobramentos na relação do sujeito com as vozes. A audição de vozes não é vista a partir de um observador externo do fenômeno, mas sim na pluralidade de formas e modos como as vozes se manifestam (MUÑOZ ET AL., 2011).

Outro aspecto que se destacou nas observações feitas diz respeito à dinâmica que se estabelece nos grupos, que difere das que ocorrem em grupos conduzidos dentro dos serviços, por estarem centrados nos compartilhamentos do cotidiano, de vivências e experiências, as quais nem sempre estão ligadas diretamente às vozes. Como observado, são muitos os momentos em que a conversa extrapola o tema das vozes e são discutidas questões como futebol, situação econômica do país, receitas culinárias etc. Enfim, há uma interação livre de protocolos pré-estabelecidos. No fragmento do diário de campo a seguir, é possível reconhecer este aspecto:

É um grupo muito interessante. A maioria dos integrantes se expressa bem, e são pessoas afetuosas, acolhedoras. Eles são muito respeitosos, diretos e francos entre si. Chama a atenção o modo como abordam os temas centrais no grupo. Não se assemelha a um grupo psicoeducativo, cognitivo-comportamental, psicodinâmico ou mesmo de medicalização. É uma abordagem psicossocial de enfrentamento dos problemas concretos da vida cotidiana. Falam sobre retomar o poder sobre sua própria vida; refletem sobre ter condições, no momento, de dirigir um automóvel, ter sua carteira de motorista renovada, distinguir se está bem ou mal, sobre cuidar de si. (ST).

Essa dinâmica de trocas sem protocolos estabelecidos, na qual cada um pode se expressar de forma livre e sincera, parece criar um ambiente rico para a busca por sentido e por estratégias de enfrentamento das vozes.

As relações de apoio mútuo e a criação de vínculos intensos também são características desses grupos. Percebe-se que, nos grupos, as relações iniciadas nos espaços de ajuda mútua ganham dimensões afetivas, as quais têm a potência de romper com o ciclo de solidão criado pelo estigma que envolve o ouvidor de vozes, especialmente no momento em que é muito necessário falar sobre esta experiência difícil e amedrontadora, como mostra o fragmento a seguir:

No grupo hoje, L. diz o que é o grupo de ouvidores de vozes para ela, enfatizando a ajuda mútua e seu percurso de medo e angústia em relação à escuta de múltiplas vozes. Fala do acolhimento, por parte de MM. (coordenador do grupo) e dos colegas, e de como tem vivido melhor com as vozes. [...] Ela enfatiza que compartilhar sua experiência the ajudou a enfrentar o medo e não se sentir só [...] diz que hoje ainda ouve vozes, mas consegue conviver com elas. (SGC).

Hoje, particularmente, o grupo foi muito intenso, e a experiência das pessoas com as vozes contribuiu para isto. As pessoas falaram coisas muito intimas, muito particulares. Falaram da experiência de ouvir vozes que os outros não ouvem. $E$ do silêncio motivado pelo medo da relação direta feita entre as vozes e a doença mental, na sociedade. (ST).

As relações e os sentimentos compartilha- 
dos nos grupos muitas vezes ultrapassam os espaços e tempos estabelecidos, envolvendo, por exemplo, as famílias dos ouvidores. Neste sentido, em alguns momentos, os vínculos emergem com mais vigor nos grupos, em especial, em situações como doenças e perdas, tal como mostra o fragmento a seguir:

A irmã de S. começou a falar e disse que elas estavam ali para agradecer ao grupo por tudo o que o grupo tinha feito pela S., que havia falecido. Contam que o grupo era uma família para S. e que, mesmo no final, quando ela quase não tinha mais forças, ela queria ir e participar [...] É realmente um momento muito emocionante. Depois de algumas poucas falas, sobre como todos estão lidando e tentando seguir adiante sem ela, as familiares vão embora, e o grupo fica em silêncio. (G).

No Grupo de San Giuseppe di Cairo, uma integrante estava afastada, em tratamento quimioterápico. Antes da finalização da reunião do grupo, fazem uma ligação telefônica, em viva voz, para ela, para cada um manifestar seu apoio e afeto. Uma visita à sua casa é combinada para o próximo final de semana, incluindo um café, em que cada um deverá levar um alimento. (SGC).

Mesmo em um contexto difícil, de perdas e adoecimentos, os grupos mostram-se como espaços férteis de crescimento individual, não só pela necessidade de enfrentamento dos processos vitais, mas também pela possibilidade de amadurecimento de relações que se estabelecem entre seus integrantes. Assim, favorecem a elaboração das experiências individuais, permitindo a descoberta de novos objetivos de vida, que não só ajudam no processo de enfrentamento das vozes, mas também retiram o ouvidor da solidão e do isolamento, abrindo-lhe novas oportunidades para uma participação mais ativa neste processo.

A exemplo disso, foram observados muitos momentos extragrupais, criados entre os participantes, os quais ocuparam espaços que possibilitaram novas formas de diálogo com a sociedade. A circulação em locais de entretenimento, arte e cultura possibilita o rompimento dos preceitos de inadequação e segregação que a experiência de ouvir vozes pode gerar. Um exemplo disto é que, sempre após o término do encontro do grupo da cidade de Gubbio, os participantes faziam o fechamento com um característico 'aperitivo' italiano, em um bar no mesmo prédio comercial em que estava localizado o Centro de Atenção Diária e onde eram desenvolvidas as atividades. $\mathrm{O}$ 'aperitivo' era marcado por interações, trocas afetivas, sorrisos e conversas.

Ao final do encontro, descemos todos ao bar. Eles me ofereceram uma bebida, me sugerindo o que estão habituados a tomar, o crodino, uma bebida amarga não alcoólica, semelhante ao aperol. (G).

Além disso, espaços como o 7th World Hearing Voices Congress, realizado na Espanha, no ano de 2015, também foram apontados pelos próprios ouvidores como importantes para a aproximação e interação entre eles, tal como relatou uma das participantes do grupo, no trecho: "Como foi bom estar em meio a tantas pessoas com experiências parecidas" (SGC). Os congressos parecem permitir que diferentes pessoas, de diferentes lugares do mundo, compartilhem experiências de enfrentamento e ampliem as possiblidades de se reapropriarem de suas próprias vidas.

Entende-se que muitos ouvidores conseguem, a partir das relações estabelecidas nos grupos, enfrentar a fase de surpresa através do compartilhamento de experiências e da criação de vínculos, que possibilitam conferir outros sentidos para as vozes. Desta maneira, são capazes de positivar suas experiências de ouvir vozes e avançar para as fases de organização, na qual ocorre o processo de seleção e comunicação com as vozes; e de estabilização, quando se desenvolvem processos mais consistentes e contínuos de lidar com as vozes (ROMME; ESCHER, 
1997). Os grupos de ouvidores de vozes têm especial papel nestas fases.

Para os ouvidores de vozes e aqueles que trabalham com os grupos de ouvidores, rotular essa experiência como 'alucinação' impede a construção de uma relação com a pessoa e discrimina aqueles que experimentam influências positivas oriundas da experiência de ouvir vozes (ROMME; ESCHER, 2012). A terminologia aliena a pessoa de sua experiência, dificulta o seu desenvolvimento e não a estimula a obter mais compreensão sobre o que está experimentando, o que não contribui na sua recuperação.

\section{Estratégias de enfrentamento}

Ao longo do processo de aprendizado para o enfrentamento das experiências com as vozes, os ouvidores compartilham diferentes estratégias para lidar com elas. Um dos primeiros movimentos tende a ser o de tentar ignorar as vozes. Contudo, tem sido consenSO (BAKER, 2012; CONTINI, 2013A; ROMME; ESCHER, 1997) que ignorar as vozes não é efetivo. A estratégia de ignorá-las, apesar de citada nos grupos e tentada por vários ouvidores, mostra-se bastante limitada. Mesmo o diálogo com as vozes e o seu controle são apresentados como desafios frente aos quais nem sempre se obtém uma resposta imediata. No entanto, Romme e Escher (1997) insistem na estratégia central de aceitar as vozes como um princípio estruturante para o autoconhecimento, para superar o medo, para efetuar as mudanças e para que o poder da pessoa sobre sua própria vida se restabeleça.

Algumas técnicas de curto prazo são utilizadas nos grupos de ouvidores de vozes, no sentido de ajudar no diálogo com elas, na obtenção de maior controle sobre as mesmas e no reconhecimento dos modos como as vozes afetam a vida do ouvidor. Sendo assim, pode-se responder às vozes; designar um tempo definido para escutar as vozes; dispensar as vozes por um determinado período; escrever o que as vozes dizem e querem dizer; verificar se o que as vozes dizem é verdade; criar fronteiras; adiar ordens; substituir diferentes ordens e aprender a expressar raiva; antecipar a voz; e falar com alguém sobre as vOZES (ROMME; ESCHER, 2000).

Destacam-se, a seguir, três técnicas utilizadas pelos participantes dos grupos acompanhados: estabelecer um diálogo com as vozes; buscar informações sobre as vozes; e escrever sobre as mesmas.

\section{ESTABELECER UM DIÁLOGO COM AS VOZES}

Nos grupos acompanhados, percebeu-se a existência da ideia de que as vozes vêm dos pensamentos e das experiências de vida do sujeito, da sua história, de sua vivência e de seu modo de lidar com as coisas da vida. A orientação que prevalecia nos grupos era para que houvesse mudança na relação com as vozes, primeiro, rompendo a fronteira do medo e, logo, reconhecendo que o problema não são as vozes em si, mas as emoções mobilizadas e modos de conviver com elas, tal como mostra o fragmento a seguir:

M. fala que tem muita dificuldade de falar com as vozes, que tem muito medo. L. fala para $M$. fazer um esforço e falar com as vozes. Ela diz que vai para o quarto e liga o rádio mais alto, até que elas desapareçam, e, às vezes, funciona. $D$. diz que talvez funcione por um tempo, mas que, se algum dia não funcionar, pensa que ela deve tentar falar com as vozes. Ela se diz ainda muito assustada para isto. As falas são no sentido de acolher e fortalecer M., que aparenta muita fragilidade. (SGC).

Uma das estratégias de enfrentamento muito presente nos grupos é a de conversar com as vozes. Se estas forem positivas, a tendência é valorizá-las; se forem depreciativas, vale tentar compreendê-las e controlá-las, de modo a recuperar o controle sobre a própria vida.

T. tem uma fala pastosa e relata que ainda se sente assustado, em muitos momentos, com as 
vozes. Mas tem feito o exercício de perguntar o que elas querem e tentar falar com elas, mesmo que isto, em alguns momentos, quando são várias vozes falando ao mesmo tempo, se torne uma tarefa difícil. (SGC).

Tal como se percebeu nos grupos, a partir do momento em que o ouvidor consegue estabelecer uma relação com suas vozes, e se apropria delas, reconhecendo quantas são, quem são e que tipo de resposta deve dar a elas, ele constrói maneiras de driblar situações que lhe parecem constrangedoras, tal como mostra o fragmento a seguir:

F. conta que, há alguns dias atrás, estava com a sobrinha, em uma sorveteria, e que a voz começou a falar com ele. Ele queria responder, mas não podia, porque a sobrinha poderia se assustar. Ele tentou ignorar a voz, mas ela era insistente. Ele conta que se levantou, foi até o banheiro, conversou com a voz e depois voltou. Diz que sabe que as pessoas não entendem. (G).

O movimento feito pelo ouvidor evidencia sua consciência de que a sociedade ainda não compreende bem esse fenômeno e que, por isto, pode se assustar quando os não ouvidores se deparam com o fato d'ele estar conversando com alguém que as demais pessoas não veem.

Essa estratégia de conversar com as vozes tem sido apontada (BAKER, 2012; COLEMAN; SMITH, 2006; CONTINI, 2013B; ROMME; ESCHER, 1997) COMO fundamental para a retomada do controle sobre a própria vida. Apesar de ser um processo difícil para o ouvidor, ele precisa, necessariamente, superar o medo inicial para, assim, aceitar as vozes, conhecê-las e positivar sua experiência com elas. Todo este processo passa pela estratégia de conversar com as vozes, que vai permitir ao ouvidor mais conhecimento sobre elas e sobre si mesmo.

O protagonismo do ouvidor de vozes fica evidente na medida em que, conhecendo suas vozes e o que elas querem, é possível retomar o controle da situação, perdido no primeiro momento. "B. afirma que, para ela, é difícil quando ouve as vozes porque ela tem que falar com elas, tentar manter o controle, $e$, às vezes, isso é muito difícil" (ST).

Um questionamento importante, colocado por muitos ouvidores de vozes nos grupos, é sobre as vozes de comando, particularmente as vozes negativas, que dão orientações e comandos para a pessoa se matar ou ferir outra pessoa. Este tema tem sido tratado com ênfase no poder de livre arbítrio da pessoa, pois o comando é da voz, mas a tomada de decisão, a ação e a consequência são sempre da pessoa. Por isto, não se pode delegar determinadas atitudes à VOZ (BAKER, 2012; CONTINI, 2013A, 2013B; ROMME; ESCHER, 1997).

Essa discussão é realizada amplamente nos grupos de ouvidores de vozes, pois se eles ferem alguém, não são as vozes que o fazem, e não são elas que respondem por tais atos. Assim, na tomada de decisões, é o ouvidor quem deve julgar, a partir de seus valores, o que deve ou não fazer. É muito interessante como este debate é potente e contribui para o ouvidor fazer o enfrentamento dos comandos da voz, dizendo-lhe que não vai fazer determinada coisa, questionando-a, enfim, posicionando-se como um sujeito com desejos, tal como ocorreu em uma das reuniões acompanhadas.

Uma questão discutida nesta reunião é o questionamento de $A$. sobre quando se deve ou não fazer aquilo que dizem as vozes. Isto gera uma discussão quando MM [coordenador do grupo] devolve a pergunta ao grupo. L. responde que depende. Os outros concordam e dizem que têm que avaliar se é certo ou errado. $M$. diz que, se a voz diz para matar alguém, ele pergunta: 'Mas, por quê?'. Uma vez a voz respondeu que estava brincando. Diz que, o que não faria, não pode fazer só porque a voz falou. Aí, é melhor pedir ajuda no grupo, no serviço. (SGC).

Outro aspecto importante, nesse sentido, diz respeito aos recursos para lidar com as vozes e à importância de protagonizar a própria existência. Em uma das reuniões do 
grupo, as ouvidoras A. e G. falaram de suas relações com o assunto, como mostra o fragmento a seguir:

A. comenta que as vozes expressam os pensamentos, o sofrimento; falam, através das pessoas, sobre suas dificuldades. Diz que é verdade que o mundo ao redor influencia nosso pensamento, mas que cada um necessita ser protagonista da sua própria vida. Fala de não delegarmos a outros e às situações externas as decisões sobre nossas vidas. O debate se trata de conviver com as vozes e manter o controle sobre sua vida, de não dar às vozes este poder. (ST).

G. conta sua história de sofrimento, diz que não se reconhecia, que não aceitava a ajuda de ninguém quando estava mal e ouvia as vozes dizendo que ela estava bem, que os outros é que pensavam que ela estava mal. Diz: 'O serviço de saúde mental é só uma parte da vida da pessoa. Não é possível que um serviço trate as pessoas como uma criança ou um idoso. A pessoa precisa ser autônoma e saber o que tem que fazer pela sua própria vida'. (ST).

Diante do exposto, a possibilidade de estabelecer um diálogo com as vozes significa superar a surpresa inicial e enfrentar, junto com seus pares, medos e dificuldades advindos da experiência de ouvir vozes, sempre protagonizando uma relação em que sua vontade e controle predominem.

\section{AMPLIAR E COMPARTILHAR INFORMAC̣ÕES: FERRAMENTAS PARA COMPREENDER A EXPERIÊNCIA}

Outra estratégia importante desenvolvida pelos participantes dos grupos é buscar informações sobre a experiência de ouvir vozes. No intuito de saber mais sobre tal vivência, além de compartilhar os desdobramentos desta em suas vidas, durante as reuniões, são discutidos aspectos relacionados ao fenômeno em si.

Como apresentado por Romme e Escher
(1997) e Coleman e Smith (2006), sobre a experiência de ouvir vozes incidem várias interpretações, entre as quais a biomédica. Entretanto, esta interpretação, embora reconhecida pelos participantes dos grupos, não é hegemônica.

A ampliação do repertório conceitual para a compreensão tem se mostrado profícua no enfrentamento das dificuldades advindas da experiência de ouvir vozes, uma vez que amplia, também, as possibilidades de domínio sobre a própria vida, por parte dos sujeitos. El-Jaick et al. $(2015$, P. 229) argumentam que

quando as informações acerca do processo de adoecimento são escassas, o cardápio de opções dos pacientes pode se afunilar, gerando prejuízos em relação às possibilidades de escolhas para o tratamento.

Os participantes dos grupos demonstram a necessidade de discutir informações sobre a experiência de ouvir vozes, bem como maneiras de acessar tais informações, o que foi citado em uma das reuniões acompanhadas, como segue:

\section{A. e F. dizem que andaram conversando, que eles gostariam de estudar mais sobre as vozes. E pro- põem que, a cada encontro, seja discutida uma temática diferente. P. [psiquiatra que participa do grupo] diz que acha uma boa ideia, e é pro- posto que seja discutido um instrumento sobre as vozes. (G).}

$\mathrm{O}$ instrumento sugerido diz respeito a um questionário conhecido como 'Hearing voices: A structured questionnaire', desenvolvido por Sandra Escher, Patsy Hage e Marius Romme. Trata-se de uma Entrevista Estruturada Maastricht, que foi uma ferramenta concebida originalmente para obter informações de pessoas que ouvem vozes e gerou um quadro mais completo de experiências compartilhadas, utilizadas para desenvolver estratégias de enfrentamento. A entrevista tem como objetivo saber mais sobre as vozes e o passado do ouvidor de voz, 
concentrando-se em cinco áreas principais: a identidade das vozes; as suas características (incluindo conteúdo); a história; os gatilhos; infância; e adolescência (ROMME; ESCHER, 2012).

Essas estratégias de enfrentamento das vozes, sistematizadas a partir desse instrumento e de outras experiências com grupos de ouvidores de vozes, que têm princípios em comum com o movimento de ouvidores de vozes, passaram a ser divulgadas em referências interligadas na Intervoice (BAKER, 2012; COLEMAN; SMITH, 2006; CONTINI, 2013A, 2013B; ROMME; ESCHER, 1997).

Entende-se que a busca por informações se constitui como um processo de formação, tida como uma

prática reflexiva que busca desenvolver a consciência crítica por parte do usuário ou cidadão para objetivos a serem desenvolvidos de acordo com sua necessidade ético-político e existencial. (RODRIGUES ET AL., 2010, P. 223).

\section{ESCREVER: COMUNICAC̣ÃO, REGISTRO E REFLEXÃO SOBRE AS VOZES}

A escrita tem funcionado como uma estratégia significativa entre os ouvidores. Conforme aponta Contini (2013A, 2013B), a partir de suas experiências com as vozes, a escrita de diários se tornou uma ferramenta importante para a interlocução com elas, e também como uma terapêutica, já que, ao escrever, sentia-se melhor.

Além de funcionar como uma forma de comunicação e de terapêutica, os dados apontam que a escrita se configura, entre os ouvidores de vozes, como um dispositivo de reflexão. Ao discutir a escrita como um dispositivo terapêutico para a psicose, Pinto e Naves (2014, P. 4) sugerem que

pensar a função da escrita como uma possibilidade de organização psíquica do psicótico é uma via possível para a clínica, pois, ao escrever, percebe-se que o sujeito expressa sua subjetividade.

As autoras alegam, ainda, que a escrita é uma maneira de conferir um sentido a uma experiência de desorganização.

$\mathrm{O}$ exercício da escrita possibilita, entre outros aspectos, um exercício de reflexão sobre si mesmo e sobre as experiências, que, ao mesmo tempo, produz sentidos para aquele que se implica na atividade. Cabe destacar aqui que, no geral, a escrita proposta nos grupos se configura como um exercício de pensamento.

Hidalgo (2008), a partir da análise do livro 'Diário de hospício', de Lima Barreto, discute uma literatura de urgência, que seria um desdobramento de uma escrita de si (Foucault), que se dá em um estado de emergência. Tal literatura, segundo a autora, delimita o momento exato da escrita como emergência, reação à situação-limite, que, por isto, se difere da escrita dos sujeitos que vivem um dia a dia comum, sem limitações que os impeçam de se libertar de uma situação opressora.

A escrita, no contexto estudado, no qual todos os participantes dos grupos eram alfabetizados, se configura também como uma forma de registro e armazenamento de informações importantes para a análise das experiências consideradas relevantes. Assim, adquire vários formatos: podem ser diários íntimos, modos de comunicação com as vozes, exercícios programáticos e pragmáticos.

Um dos exercícios feitos no grupo SGC foi a utilização de um instrumento que se baseava em um relato individual de um exercício escrito, no qual cada participante anotava o que gostaria de mudar em sua vida, em relação às vozes, no ano novo que se aproximava. $\mathrm{O}$ fragmento a seguir mostra como tal exercício foi discutido no grupo:

Em seguida, cada um relata seu exercício. As falas concentram-se em expectativas em viver melhor com as vozes no próximo ano, não ter conflitos familiares, estudar, trabalhar, namorar, 
se apaixonar. Apenas M. tem como projeto 'Não ouvir mais as vozes'. (SCG).

A efetividade dessa estratégia também pode ser relacionada à produção de sentidos para as experiências de ouvir vozes. Tal produção parece auxiliar não apenas no enfrentamento das situações que geram algum tipo de sofrimento psíquico, mas também na constituição de um registro de experiências, que serve de suporte para situações futuras.

\section{Considerações finais}

Construir estratégias para enfrentar sofrimentos e dificuldades advindos da experiência de ouvir vozes tem se mostrado uma possibilidade importante para os sujeitos que têm participado tanto dos grupos de ouvidores de vozes quanto do movimento mais amplo e da rede internacional, a Intervoice.

Como apontado até aqui, tais grupos constituem-se enquanto recursos terapêuticos relevantes para os sujeitos. Ainda que os grupos sejam heterogêneos em termos de organização e funcionamento, no contexto estudado percebemos algumas características comuns, tais como: a criação de vínculos e a constituição de suporte emocional para o enfrentamento de dificuldades entre os participantes. Outra característica comum, encontrada nos grupos estudados, é a autoajuda/ajuda mútua, o que confere a tais grupos uma dinâmica singular, que escapa aos saberes instituídos e estabelece outra relação com o saber produzido por seus participantes, a partir de suas experiências.

As estratégias que emergem das experiências dos sujeitos nesses grupos, especialmente as discutidas aqui, indicam a relevância do protagonismo desses sujeitos na construção de recursos terapêuticos para seus sofrimentos. Outrossim, revelam ferramentas a serem exploradas no campo da saúde mental, tais como a escrita, a formação e a informação dos sujeitos.

Os grupos de ouvidores de vozes, como apresentado, conferem um lugar central para os sujeitos, que, no compartilhamento de suas experiências, passam a estabelecer outra relação com as vozes. Ainda que tais grupos estejam se desenvolvendo em contextos socioculturais específicos, é possível reconhecer suas possibilidades de constituição em outros países.

Por fim, destacam-se algumas limitações relacionadas não somente ao registro detalhado em diário de campo pelas pesquisadoras no idioma italiano (com posterior tradução para a língua materna de ambas, o português), mantendo o compromisso de refletir o que aqueles sujeitos, naquele contexto cultural, estavam trazendo, mas também relacionadas ao processo de saída de campo, que se configurou como um caminho de delicada construção, considerando o fato de terem passado a conviver intimamente com os sujeitos. Ressalte-se, por fim, que este trabalho busca contribuir com a ainda limitada produção sobre o tema 'ouvir vozes', evidenciando a perspectiva do sujeito que ouve vozes, de modo a contribuir com o deslocamento da interpretação tradicional.

\section{Contribuições}

Os autores participaram igualmente de todas as etapas da construção do artigo. 


\section{Referências}

BAKER, P. The voice inside: a practical guide to coping with hearing voices. [S. 1.]: Paperback, 1998. Disponível em: <https://southbayprojectresourcedotorg.files.wordpress.com/2015/09/a-practical-guide-to-coping-with-hearing-voices.pdf $>$. Acesso em: 19 abr. 2017.

BARROS, O. C.; SERPA JÚNIOR, O. D. Ouvir vozes: um estudo sobre a troca de experiências em ambiente virtual. Interface, Botucatu, v. 18, p. 557-569, jul. 2014. Disponível em: <http://www.scielo.br/scielo. php?pid=S1414-32832014000300557\&script=sci abstract\&tlng=pt>. Acesso em: 19 abr. 2017.

CARDANO, M.; LEPORI, G. Udire la voce degli dei: L'esperienza del gruppo voci. Milano: Franco Angeli, 2012.

COLEMAN, R.; SMITH, M. Lavorare con le voce. Torino: EGA, 2006

CONTINI, C. Sentire le voce: manuale di affrontamento. Vignola: Self Publishing, 2013a.

Sentire le voce: manuale di afrontamento: esercizario per l'uditore. Vignola: Self Publishing, 2013b.

EL-JAICK, F. S. et al. Usuários da saúde mental como educadores: o que suas narrativas podem nos ensinar. Interface, Botucatu, v. 20, n. 56, p. 227-238, nov. 2015. Disponível em: <http://www.scielo.br/scielo. php?pid=S1414-32832016000100227\&script=sci abstract\&tlng=pt>. Acesso em: 19 abr. 2017.

HATTON, T. J. Immigration, public opinion and the recession in Europe. Economic Policy, Londres, v. 31, n. 86, p. 205-246. 2016. Disponível em: <http://cepr. org/sites/default/files/events/988_HATTON\%20 -\%20Immigration,\%20Public\%200pinion\%20and\%20 the\%20Recession\%20in\%20Europe.pdf $>$. Acesso em: 19 abr. 2017.

HIDALGO, L. A loucura e a urgência da escrita. Alea, Rio de Janeiro, v. 10, n. 2, p. 212226, 2008. Disponível em: <http://www.
scielo.br/scielo.php?script=sci_arttext\&pid=S1517-106X2008000200005>. Acesso em: 19 abr. 2017.

JAYNES, J. The origin of consciousness in the breakdown of bicameral mind. Nova Iorque: Houghton Mifflin; Marines Books, 2000.

MUÑOZ, N. M. et al. Pesquisa clínica em saúde mental: o ponto de vista dos usuários sobre a experiência de ouvir vozes. Estudos de Psicologia, Natal, v. 16, v. 1, p. 83-89, jan./abr. 2011. Disponível em: <http://www. scielo.br/pdf/epsic/v16nl/allvl6nl.pdf>. Acesso em: 19 abr. 2017

NUNES, M. O.; TORRENTÉ, M. Abordagem etnográfica na pesquisa e intervenção em saúde mental. Ciência \&̇ Saúde Coletiva, Rio de Janeiro, v. 18, n. 10, p. 2859-2868, out. 2013. Disponível em: <http:// www.scielo.br/scielo.php?script=sci_arttext\&pid $=$ S1413-81232013001000010 $>$. Acesso em: 19 abr. 2017.

PINTO, A. L.; NAVES, E. T. A escrita de si: um estudo psicanalítico sobre a clínica da psicose. Perspectivas em Psicologia, Uberlândia, v. 18, n. 1, p. 3-25, jan./jul. 2014.

RODRIGUES, J. et al. Formação política dos integrantes de uma associação de usuários de saúde mental. Cadernos Brasileiros de Saúde Mental, Florianópolis, v. 2, n. 4-5, p. 213-224, 2010. Disponível em: <https:// repositorio.ufsc.br/handle/123456789/102348>. Acesso em: 19 abr. 2017

ROMME, M.; ESCHER, S. Making Sense of Voices: a guide for mental health professionals working with voice-hearers. Londres: Mind Publications, 2000.

Na companhia das vozes: para uma análise da experiência de ouvir vozes. Lisboa: Estampa, 1997.

Psychosis as a personal crisis: an experience based approach. Nova Iorque: Routledge, 2012.

RUDDLE, A.; MASON, O.; WYKES, T. A review of 
hearing voices groups: Evidence and mechanisms of change. Clinical Psychology Review, Nova Iorque, v. 31, n. 5, p. 757-766, jul. 2011. Disponível em: <https://www. ncbi.nlm.nih.gov/pubmed/21510914>. Acesso em: 19 de abr. 2017.

ZANNI, G. Come nasce un gruppo di auto mutuo aiuto per uditori di voci. 2017. Disponível em: <http://www. parlaconlevoci.it/gruppi.php>. Acesso em: 19 de abr.

2017.

Recebido para publicação em maio de 2017

Versão final em outubro de 2017

Conflito de interesses: inexistente

Suporte financeiro: pesquisa financiada pela Coordenação de

Aperfeiçoamento de Pessoal de Nível Superior (Capes) 